\title{
Differentiated assessment of the recreational potential of forests in the management of recreational forests
}

\author{
Haris G. Musin ${ }^{1}$, Stanisłav V. Denisov ${ }^{1}$, Ildar I. Khalilov ${ }^{2, *}$, and Azat R. Minnichanov ${ }^{1}$ \\ ${ }^{1}$ Kazan State Agricultural University, 420015 Kazan, Russia \\ ${ }^{2}$ Department of Rosselkhoznadzor of the Republic of Tatarstan, Kazan, Russia
}

\begin{abstract}
The assessment of the recreational potential is the primary basis for forest cadaster, which contains reliable information on natural, economic and legal conditions of the forest fund and forest users. Depending on the role and importance of diagnostic features in landscape formation, they receive a differentiated assessment. Differentiated assessment of recreational potential criteria is a critical basis of cadastral land assessment, which promotes optimal decisions to improve recreational properties of landscapes and ensures protection and rational use. It allowed some neighborhoods to be excluded from the recreational use, others - to limit this use, third - to identify additional opportunities for forest land leasing. On the same basis, options have been proposed to redistribute the flow of recreational people by forming forest parks on the basis of existing forests and forest landscapes.
\end{abstract}

\section{Introduction}

The role of forests as a recreational resource is indispensable since it bears health and relaxation effect due to ionizing and phytoncidal properties of plants. The role of forests is enormous, and it is they that contribute to cleaning, decontamination and moisturization of air. The management of recreational forests is caused by some complicating factors (increased anthropogenic load, forest management in green areas), which creates the need for specialized approaches to differentiated assessment of the recreational potential of forests.

\section{Purpose of the study}

To study methods to assess recreational potential of recreational forests for recreational forest management.

\section{Relevance of the topic}

At the present historical stage, when for the first time in the history of forestry the recreational forest management has acquired independent status (art. 25 of the Tax Code of the Russian Federation), there is a need to shift from qualitative indicators, often blurred and not comparable, to quantitative ones.

\section{Objects of research}

Forest Fund of the Russian Federation.

\section{Analysis and discussion of methods}

Therefore, the methodology of recreational assessment gave rise to several directions:

1. Stages of recreational digression of forest stands are established $[5,14]$.

2. The leading features of landscapes are accepted contrast of relief forms, mosaic and typological spectrum of forests, their aesthetic qualities, water bodies, lands [8], which is truly an assessment on a landscape basis [4].

3. Comprehensive assessment of recreational potential of forests is determined by attractiveness, comfort and sustainability. The guidelines on engineering and environmental surveys for recreational areas in Moscow, when determining the recreational potential of forests, along with benchmark indicators (composition, age structure, average values of height and diameter of a tree stand, growth class, completeness, reserve of raw-growing and dry-resistant forest) provides for the use of special scales to define additional characteristics - type of spatial structure, category of sanitary state of planting, sanitary and hygienic, aesthetic and recreational assessments, as well as the degree of degradation of forest environment. The stand-wise assessment of the forest mass on twenty-nine indicators is combined into three main groups: forest attractiveness, its comfort for tourists and resistance to recreational impact. All indicators are assessed on a five-point scale (from 0 to 4 points). For integral assessment of recreational potential, the forest stand is divided into four classes of recreational value (CRV). Such an integrated system of assessment indicators covers the whole set of criteria that take into account biological,

* Corresponding author: halilov1985@mail.ru 
humanitarian and socio-economic needs of recreational people [13].

System of economic assessment of recreational forests [1].

When developing the concept of the green zone in Kazan, we used a differentiated point assessment of ecological productivity of forest stands taking into account their recreational characteristics, forestrytaxation and structural indicators. As an integral indicator, it is obtained by translating a set of natural values into a single dimensionless numerical scale with fixed boundaries taking into account the role of each diagnostic feature. In general, the recreational potential of the territory is calculated according to the formula:

$$
R P T=\sum_{1}^{7} R+\sum_{1}^{9} C H R+\sum_{1}^{4} P R,
$$

where RPT - recreational potential of the territory;

$\mathrm{R}$ - natural resources (climatic, balneological, hydrological, speleological, animal life, forest fund, timber landscapes);

CHR - cultural and historical resources (monuments of nature, history and architecture, ethnographic and folklore heritage, parks, gardens, forest parks and dendroparks);

PR - production resources (engineering and technical structures, unique technological processes, labor skills and historical unique crafts).

Regarding natural resources in this work we will study in more detail the role of forest in the formation of recreational potential of the territory since the efficiency of the forest to perform medium-forming, landscape-and biosphere-stabilizing, oxygen-producing, waterprotecting and water-regulating functions and the possibility to neutralize technogenic, recreational and other loads is very high [7]. The use of the entire positive aggregate of forest impact on the environment to create a favorable ecological environment (FEE) is the defining task of recreational forest management [2].

Comparative assessment of natural or technogenic landscapes by their attractiveness and recreational capacity at comparable levels of culture and intensity of forest management based on their objective features and properties both natural and acquired in the process of forest management allows determining how one landscape or its components exceed others, optimizing both their individual properties and their combination.

Not all parameters here are equal, equivalent in the formation of recreational potential of the territory. Some of them are leading, more valuable, others are less significant, co-relevant, i.e. the starting point is the fact that the diagnostic signs in these specific conditions cannot be equivalent in the formation of the recreational potential.

The essence of differential consideration of the role of diagnostic signs in the formation of the recreational potential is reduced to the assessment of the landscape by internal properties correlated with its attraction. Thus the correlation coefficients are as follows: with species composition -0.74 ; with his age -0.71 ; origin -0.57 ; height -0.62 ; aesthetic properties - 0.70; type of landscape -0.51 , etc.
Under this approach, the sum of all characteristics against which the potential of an object is assessed in their maximum or optimal value is taken as 100. Each characteristic is individually assigned a score according to its role in the formation of the resource.

Thus, the recreational forest assessment (recreational usefulness, recreational utility and attractiveness, landscape or aesthetic assessment) is a quantitative expression of the forest's fitness (comfortable conditions) for recreation and tourism in points depending on the time of year and the state of weather. By adjusting the attractiveness of forest planting, the correctness of diagnostic landscape-forming signs is established. Depending on the role and importance of diagnostic forming features in landscape formation, they receive a differentiated score. All parameters of natural recreational potential consist of eight groups characterized by certain physical values (Table 1 ).

$$
\begin{array}{rl}
R P=\sum_{1}^{6} C p+\sum_{1}^{31} & F c \\
& +\sum_{0}^{7} W r \\
& +\sum_{0}^{5} F a g r \\
& +\sum_{0}^{2} A+\sum_{0}^{2} B r+\sum_{0}^{2} S p l+\sum_{1}^{4} R,
\end{array}
$$

where RP - recreational potential of the natural landscape;

$\mathrm{Cp}$ - climate-forming parameters; $\mathrm{Fc}$ - recreational capacity of forests;

$\mathrm{Wr}$ - water resources;

Fagr - timber landscape;

A - animal world;

$\mathrm{Br}$ - balneological resources;

Spl - speleological resources;

$\mathrm{R}$ - relief.

The combination of several factors increases the recreational potential of the territory: "the beauty of the whole area is connecting forest with water..." (Aksakov). Therefore, correction factors are applicable. If there are multiple for the same area, the largest one is used. The availability of drinking water supplies remains a common requirement.

The estimated score of each indicator is calculated by the formula:

$$
B=\frac{P_{a} * 100}{P_{m}}
$$

where $\mathrm{B}$ - score; $\mathrm{Pa}$ - actual value of estimated forest stands; $\mathrm{Pm}$ - value of indicator taken as the maximum (optimal) value. With such differential approach, an estimated score is defined as a weighted score by the correlation coefficient between diagnostic parameters and the sum of points of certain indicators:

$$
O_{s}=\frac{b_{1} r_{1}+b_{1} r_{1}+\cdots+b_{n} r_{n}}{r_{1}+r_{2}+\cdots r_{n}}
$$

where $\mathrm{O}_{\mathrm{s}}$ - overall score; $b_{1}, b_{2}, b_{n}$ - points of individual deposition indices; $\mathrm{r}_{1}, \mathrm{r}_{2}, \mathrm{r}_{\mathrm{n}}-$ correlation coefficients. 
Table 1. Recreational potential parameters

\begin{tabular}{|c|c|c|}
\hline Parameters & Indicator & $\begin{array}{c}\text { Unit of } \\
\text { measurement }\end{array}$ \\
\hline \multirow{6}{*}{$\begin{array}{l}\text { Climate-forming } \\
\text { parameters }\end{array}$} & Weather conditions: temperature mode & ${ }^{\circ} \mathrm{C}$ \\
\hline & Hydrothermal index & unit \\
\hline & Relative humidity & $\%$ \\
\hline & Wind velocity & $\mathrm{m} / \mathrm{sec}$ \\
\hline & \begin{tabular}{|l|} 
Sunshine \\
\end{tabular} & day \\
\hline & \begin{tabular}{|l|} 
Season \\
\end{tabular} & share unit \\
\hline \multirow{32}{*}{$\begin{array}{l}\text { Recreational } \\
\text { capacity of forests }\end{array}$} & Area & ha \\
\hline & Species composition & share unit \\
\hline & Age & year \\
\hline & Origin & natural, artificial \\
\hline & Height & $\mathrm{m}$ \\
\hline & Diameter & $\mathrm{cm}$ \\
\hline & Density & share unit \\
\hline & Growth class & share unit \\
\hline & Forest type & share unit \\
\hline & Stock & $\mathrm{m}^{3}$ \\
\hline & Growing stock increment & $\mathrm{m}^{3} /$ ha year \\
\hline & Undergrowth & share unit/pcs \\
\hline & Underwood & share unit/pcs \\
\hline & Forest live cover & share unit \\
\hline & Non-timber forest resources & type, $\mathrm{kg} / \mathrm{ha}$ \\
\hline & Soil & - \\
\hline & Animal life & head/ha \\
\hline & Type of landscape & unit \\
\hline & Degree of degression & unit \\
\hline & Attractiveness & person/ha \\
\hline & Hygienic quality & - \\
\hline & Oxygen release & $\mathrm{t} / \mathrm{ha}$ \\
\hline & Carbon sequestration & $\mathrm{t} / \mathrm{ha}$ \\
\hline & Air ionizing & th.pcs $/ \mathrm{cm}^{3}$ \\
\hline & Phytoncidal nature & $\mathrm{kg} / \mathrm{ha}$ \\
\hline & Dust filtration and accumulation of microelements & $\mathrm{kg} / \mathrm{ha}$ \\
\hline & Acoustic comfort & $\mathrm{dB}$ \\
\hline & Aesthetics & share unit \\
\hline & Class of fineness & share unit \\
\hline & \begin{tabular}{|l|} 
Stability \\
\end{tabular} & share unit \\
\hline & Species & unit \\
\hline & Comfort & unit \\
\hline \multirow{5}{*}{$\begin{array}{l}\text { Recreational } \\
\text { capacity of forest- } \\
\text { agrarian landscapes }\end{array}$} & Area & ha \\
\hline & Visibility depth & $\mathrm{m}$ \\
\hline & Botanical composition of grass & pcs \\
\hline & \begin{tabular}{|l|} 
Forest cover \\
\end{tabular} & $\%$ \\
\hline & Attractiveness & person/ha \\
\hline \multirow[t]{7}{*}{ Water resources } & Temperature mode & ${ }^{\circ} \mathrm{C}$ \\
\hline & Springs and their flowrate & $1 / \mathrm{sec}$ \\
\hline & Chemical composition & $\mathrm{g} / \mathrm{l}$ \\
\hline & Flow velocity & $\mathrm{m} / \mathrm{sec}$ \\
\hline & Water area & ha \\
\hline & Fish fauna composition & pcs \\
\hline & Resources & $\mathrm{kg}$ \\
\hline \multirow{2}{*}{$\begin{array}{l}\text { Balneological } \\
\text { resources }\end{array}$} & Quantity & unit \\
\hline & Yield & $1 / \mathrm{sec}$ \\
\hline \multirow{2}{*}{$\begin{array}{l}\text { Speleological } \\
\text { resources }\end{array}$} & Type & pcs \\
\hline & Quantity & pes \\
\hline \multirow[t]{2}{*}{ Animal world } & Animal species & pcs \\
\hline & Animal numbers & pcs \\
\hline \multirow[t]{4}{*}{ Relief } & Compartmentalization & $\mathrm{km} / \mathrm{sq} . \mathrm{km}$ \\
\hline & Drainage relief & $\mathrm{m}$ \\
\hline & Slope angle & degree \\
\hline & Exposition and slope length & $\mathrm{m}$ \\
\hline
\end{tabular}


This method of points allocation allows considering the role and share of participation in the formation of ecological productivity of each diagnostic indicator, which are quite different.

Thus, the proposed method of determining the recreational potential of forests is based on a differential assessment of indicators according to their importance. With this approach, the sum of all indicators for which recreational potential is determined in their maximum value is taken for 100 points.

All factors that do not appear in the table and affect the recreational potential of forests are taken into account as correction factors.

These are the principles for quantifying the recreational potential of forests. The definition of its specific value is an objective basis for solving a number of organizational and economic issues and carrying out forest activities to increase forest productivity. Especially in market conditions, when leasing forests, it is necessary to know exactly the specific parameters of not only wood, biological, ecological productivity of forests, but also of their recreational potential.

This recreational potential assessment is the primary basis for forest cadaster, which contains reliable information on natural, economic and legal conditions of the forest fund and forest users. In market conditions, under different forms of forest ownership, the assessment of recreational potential is a prerequisite, both to stimulate forest production within lease and change of forest ownership, and for the cadastral valuation of land.

Aimed at creating a tax base for the calculation of land tax [3, 9-12], it is a systematic set of data containing qualitative and quantitative inventory of forests. Although according to the Tax Code of the Russian Federation, the forest fund lands are not subject to taxation and do not participate in the formation of the consolidated budget of administrative regions, during leasing and concessions the fee for the forest plot depends on its cadastral value. It does not match the market value and can exceed the sales price multiple times.

The specific cadastral value of forest land determined on the basis of the capitalization of annual estimated rental income derived from the economic use of land is usually lower than the agricultural land, for example, in Leningrad region it is 72 kopeks per $1 \mathrm{~m}^{2}$, while the value of agricultural land is estimated as 7 rubles 24 kopeks, i.e. 10 times more expensive, which is quite disputable. This rather indicates the imperfect nature of methods for calculating the specific cadastral indicator the cadastral value of the forest fund land.

The price variation of agricultural lands is already observed, while forest lands have a wider range of value fluctuations since forests have different composition, age and productivity.

Therefore, E.A. Lagutenko, L.M. Vaitukevich [6] in determining the specific cadastral indicator of the cadastral value of forest lands or individual forestry introduced correction factors of the forest stand reserve and recreational dignity of forest lands according to four categories (very high -0.1 ; low -0.4 ).
Today, when it is not possible to find a solution to such key environmental and economic problems of forest management as adequate pricing of recreational resources, planning and financing of forest reproduction, guaranteeing the preservation of their resource and protective capacities fully meeting the recreational needs of the population, differentiated assessment of recreational capacity criteria serves the basis of cadastral land assessment, promotes optimal decisions to improve the recreational properties of landscapes, ensures their conservation and rational use. It allowed some neighborhoods to be excluded from recreational use, others - to limit, third - to identify additional opportunities for leasing.

On the same basis, it was proposed to redistribute the flow of recreational people by forming forest parks on the basis of existing forests and forest landscapes.

\section{Conclusion}

Demanded recreational resources become the basis of economic development of the regions. However, a number of issues need to be adjusted, especially the amount of rent. It is now established without taking into account the ecological productivity of stands (it is the same for century-old pine forests near the water area and for uniform aspen forest). The rent established in a differentiated manner depending on environmental productivity will allow increasing the income to the budget by 1.5-2 times. If the price of the environmental productivity score is correctly determined in monetary terms, it is possible to use not expensive or arbitrary, but market mechanisms to form the cost of a favorable ecological environment.

\section{References}

1. V.P. Kozhevnikov et al., Forest resources of the Ural for recreation and tourism (USTU, Ekaterinburg, 2009)

2. V.Ya. Kuramshin, Management in recreational forests (Moscow, 1988)

3. E.A. Lagutenko, L.M. Vaitukevich, Determination of cadastral value of forest fund lands, Current problems of the forest code, 25, 216-218 (BSITU, Bryansk, 2010)

4. N.A. Lugansky, S.V. Zalesov, V.A. Shchavrovskiy, Forestry (USFTU, Ekaterinburg, 1996)

5. I.S. Melekhov, Forestry (Agropromizdat, Moscow, 1989)

6. R.F. Tax, Code dated 05.08.2000 no. 117-FZ as amended on 05.04.2010 no. 41-FZ. Retrieved from: http://www.consultant.ru.

7. Resolution of the Government of Leningrad Region "On the Approval of Results of the State Cadastral Assessment of Forest Lands in the Territory of Leningrad Region”, no. 76 of 30.03.2010. Retrieved from: http://www.consultant.ru. 
8. Resolution of the Government of the Russian Federation "On the Approval of the Rules for State Cadastral Land Assessment", no. 316 of 08.04.2000 as amended on 17.09.2007 no. 590. Retrieved from: http://www.consultant.ru.

9. Resolution of the Government of the Russian Federation "On State Cadastral Assessment of Lands", no. 945 of 25.08.1999. Retrieved from: http://www.consultant.ru.
10. S.L. Rysin, Assessment of recreational potential of forest stands as the most important component of forest inventory in urbanized territories, Current issues of the forest code, 25, 59-62 (BSITU, Bryansk, 2010)

11. V.P. Chizhova, Recreational load in recreation areas (Forest Industry, Moscow, 1977) 